\title{
Effects of Irradiation with Light of Different Photon Densities on the Growth of Young Green Barley Plants
}

\author{
Tianxiao Meng1, Eriko Nakamura², Nobuto Irino ${ }^{2}$, Khem Raj Joshi ${ }^{3}$, \\ Hari Prasad Devkota ${ }^{3}$, Shoji Yahara ${ }^{3}$, Ryuichiro Kondo ${ }^{1^{*}}$ \\ ${ }^{1}$ Faculty of Agriculture, Kyushu University, Fukuoka, Japan \\ ${ }^{2}$ Asahi Ryokuken Co., Ltd., Fukuoka, Japan \\ ${ }^{3}$ Graduate School of Pharmaceutical Sciences, Kumamoto University, Kumamoto, Japan \\ Email: ryukondo@agr.kyushu-u.ac.jp
}

Received 25 January 2015; accepted 9 February 2015; published 13 February 2015

Copyright (C) 2015 by authors and Scientific Research Publishing Inc.

This work is licensed under the Creative Commons Attribution International License (CC BY). http://creativecommons.org/licenses/by/4.0/

(c) ()

\section{Abstract}

In recent years, young green barley has been increasingly used as a functional food ingredient. Studies have shown that cultivated young green barley has different levels of amino acids, vitamin $\mathrm{C}$, and polyphenol content depending on the harvest time. Furthermore, some studies have investigated the effect of the growing conditions on cultivated barley in particular the use of light-emitting diodes (LED). Young green barley was exposed to three light sources of different wavelengths (sun light [ASL], light-emitting diode [LED] - Red 9 + Blue 1 [LED-R9:B1], LED - Red 4 + Green 1+ Blue 1 [LED-R4: G1:B1]). Under light with photon densities of $200 \mu \mathrm{mol} \mathrm{mL} \mathrm{L}^{-2} \cdot \mathrm{s}^{-1}$, the dry weight of young green barley was not affected, while the differences were observed in the morphology of the underground portion of the plant (roots) depending on the light source. The roots of the plant grown in ASL weighed twice as much as those that were grown under LED irradiation. Furthermore, LED irradiation caused an increase in the amino acid content in plants; the amino acid content of plants grown under LED-R9:B1 was twice as much as that grown under ASL irradiation. Four kinds of cyanogenic glucosides (CGs) were isolated, identified, and their levels were measured. The plant grown under LED-RGB irradiation, including LED-G, produced approximately $20 \%$ more CGs as compared to the plants grown under the other two light sources. Thus, it was inferred that young green barley exhibited a stress response under LED-G light and accumulated CGs in the stems and leaves with prepare for any damage that may occur on the leaf surface. The nitrogen (N) content in the root was the lowest, while the CG content was the highest in the plant grown under LED-RGB irradiation. It is inferred that the $\mathrm{N}$ content decreased because $\mathrm{N}$ was eliminated from the roots to allow for accumulation of CGs response to stress. In general, the growth experiments to use an irradiation condition in which the distance between the light source and plant floor is ${ }^{*}$ Corresponding author.

How to cite this paper: Meng, T.X., Nakamura, E., Irino, N., Joshi, K.R., Devkota, H.P., Yahara, S. and Kondo, R. (2015) Effects of Irradiation with Light of Different Photon Densities on the Growth of Young Green Barley Plants. Agricultural Sciences, 6, 208-216. http://dx.doi.org/10.4236/as.2015.62020 
fixed. It is not clear whether the photon density level received by the top leaves is fixed according to plant growth, by changing the height of plant growing shelf. Therefore, against this background, when the photon density was increased from 200 to $300 \mu \mathrm{mol} \mathrm{mL} \mathrm{mL}^{-2} \cdot \mathrm{s}^{-1}$ under ASL irradiation, only a minimal change was observed in the root weight, while the weight of the part of the plant above the ground surface (stems and leaves) increased by approximately $30 \%$, with a $10 \%$ increase in the amino acid content.

\section{Keywords}

Young Green Barley, Light-Emitting Diode, Cyanogenic Glucosides, Amino Acid, Tocopherol

\section{Introduction}

In recent years, young green barley has been increasingly used as a functional food ingredient. The majority of studies on young green barley plants have focused on the antioxidant activity of secondary metabolites, such as phenolic compounds, whose primary components are flavonoids including saponarin and lutonarin [1]-[4]. Meanwhile, studies have shown that cultivated young green barley has different levels of amino acids, vitamin C, and polyphenol content depending on the harvest time [5]. Furthermore, some studies have investigated the effect of the growing conditions on cultivated barley in particular the use of light-emitting diodes (LED), which has been developed in recent years, as a light source, aside from conventional fluorescent lights [6]. Furthermore, studies on the production of secondary metabolites have reported that the antioxidant activity derived from ingredients such as phenol components and vitamin $\mathrm{C}$ would increase by the addition of 16\% LED-B (blue) to LED-R (red) [7]. Based on these results, Unbonaviciute et al. suggested that LED-R might be the cause of light stress due to the increase in secondary metabolite production in young green barley [7].

Some studies have reported that there is a correlation between cyano glucoside (CGs) content and $\mathrm{N}$ content [8] [9]. CGs exist in many plants and protect the plant from infections and herbivorous animals. A number of studies have focused on the corn plant, which is one of the main cereal crops [10] [11]. In addition, the significance of GC biosynthesis as a method of accumulating $\mathrm{N}$ sources has been reported, and this mechanism is indispensable for plant growth [8]. Furthermore, Moller et al. reported that CGs function as an $\mathrm{N}$ and glucose transporter [12]. In corn plants, the synthesis and accumulation of CGs occurs under dark conditions [13], while the amount of CGs decreased under strong light conditions. Moller et al. suggested that this was because CGs were broken down to eliminate active oxygen generated by stress under strong light, and that the products released acted as scavengers to defend the plant body against damage [12]

Our previous research showed that the amino acid content in plants increased when they were grown under LED-R9:B1 irradiation compared with that under natural sunlight and that the difference observed under the two light sources was related to the amount of amino nitrogen accumulated as well as the amount of CGs [14]. The amount of CGs reported under different conditions in the present study is consistent with those of a pervious study that showed [7] that LED irradiation, particularly LED-R, induced stress in young green barley. The use of LED-R and LED-G enhances the antioxidant properties of young green barley, and research suggests that these light sources led to an increase in phenolic component content [6]. In addition, it was reported that flavonoids content increase in buckwheat plant grown under conditions of mixed LED R:G:B = 4: 1:1 irradiation [15]. The report has suggested that LED-G may regulate plant growth under LED-R, LED-B, and far-red (FR) light [16]. Furthermore, it was reported that LED-G is important for $\mathrm{CO}_{2}$-fixation in the mesophyll of spinach [17], and the importance of green light in LED was suggested.

It is common, however, for growth experiments to use an irradiation condition in which the distance between the light source and plant floor is fixed. It is not clear whether the photon density level received by the top leaves is fixed according to plant growth, by changing the height of plant growing shelf. Therefore, against this background, we examined the effects of different irradiation conditions i.e., artificial sun light (ASL), LED-R9:B1, and LED-R4:G1:B1 under controlled same photon densities, on the growth and morphology of cultivated barley plants. 


\section{Materials and Methods}

\subsection{Plant Material and Growth Conditions}

Two-rowed barley (Hordeum vulgare f. distichon) Nishinohoshi was harvested in 2014. Seeds were sown in planters $\left(41 \mathrm{~cm} \times 20 \mathrm{~cm}\right.$, soil area $820 \mathrm{~cm}^{2}$ ) containing organic fertilizers (SHOEI, Miyazaki, Japan) in a biotron growth chamber at $15^{\circ} \mathrm{C}-20^{\circ} \mathrm{C}, 70 \%$ relative humidity.

LEDs (Model 3LH-256; Nippon Medical and Chemical Instrument Co., Ltd., Japan) tested in biotron chamber were shaded by an aluminum sheet. Artificial Sun-Lights (ASL: Model DR400/TL; Toshiba Lighting \& Technology Components Corporation Ltd., Japan) was used as a control light in biotron growth chamber. Young green barley plants were divided into three groups, one group was the artificial sun-light (control group), and the other two groups were as treatment groups, first group growth under a mixture of $90 \%$ red $+10 \%$ blue LEDs light (LED-RB) and the second group growth under a mixture of $80 \%$ red $+10 \%$ green $+10 \%$ blue LEDs light (LED-RGB) (treatment groups). In the growth chamber the photoperiod was $12 \mathrm{~h}$ and $12 \mathrm{~h}$ dark per day during the whole experiment. Each group was harvested on the $5^{\text {th }}, 10^{\text {th }}$ day after germination, and the plant height and weight were quantified as growth parameters.

\subsection{Determination of Photon Flux Density}

The three light sources were artificial sun light, LED-RB and LED-RGB. Red, green and blue LEDs have a peak emission at $660 \mathrm{~nm}, 550 \mathrm{~nm}$ and $450 \mathrm{~nm}$, receptivity. ASL planters were placed on $85 \mathrm{~cm}$ steel shelves under ASL light in the biotron. Each LEDs light source was set at $20 \mathrm{~cm}$ from the surface of the planter soil. Photon density was measured (Model-101EG, Nippon Medical and Chemical Instrument Co., Led., Japan) at soil level of each planter. Response to the growth of the young green barley, adjustment once a day the position of the planter that the light intensity of three light sources were setting at 200 or $300 \mu \mathrm{mol} \mathrm{ml} \mathrm{m}^{-2} \mathrm{~s}^{-1}$ over the top of shoots, respectively.

\subsection{Determination of Amino Acids Composition}

Amino acids (except for tryptophan) in the young green barley plants on $15^{\text {th }}$ day after germination cultivated under the three light sources were determined by a JLC-500/V automatic amino acid analyzer (JEOL Co., Ltd., Japan), and tryptophan in the young green barley was measured by an LC-20AD solvent delivery unit (Shimadzu Corporation, Ltd., Japan). The sample dry weight of ASL light plants $(n=207)$ was 4.6g, that of LED-RB plants $(\mathrm{n}=358)$ was $7.2 \mathrm{~g}$, and that of LED-RGB plants $(\mathrm{n}=226)$ was $4.1 \mathrm{~g}$.

\subsection{Extraction and Isolation of Cyanogenic Glucosides}

The young green barley cultivated under three light sources was extracted with 30\% Methanol, and extracts were subjected to MCI gel CHP-20P (75 - $150 \mu \mathrm{m}$, Mitsubishi Kasei Co., Japan) column chromatography and eluted with water and 10\% methanol. Osmaronin and epidermin were obtained from 10\% methanol fraction. Methanol eluted fractions were subjected to ODS column chromatography and eluted 5\%, 7\%, and 100\% methanol. Epiheterodendrin was obtained from the fractions eluted with 5\%, 7\% methanol. Sutherlandin was obtained from fractions eluted with $5 \%$ methanol. Structures of these compounds were elucidated on the basis of ${ }^{1} \mathrm{H}-\mathrm{NMR}$ (JEOL, $500 \mathrm{MHz}$ ) and ${ }^{13} \mathrm{C}-\mathrm{NMR}$ (JEOL, $125 \mathrm{MHz}$ ) spectral data and with literature values [9] [18].

\section{Results}

\subsection{Effect of Irradiation from Three Sources of Light with a Photon Density of $200 \mu \mathrm{mol} \mathrm{mL} \mathrm{L}^{-2} \mathrm{~S}^{-1}$ on the Morphology of Young green Barley}

No significant difference was found in the growth of the aboveground part of plants, such as stems and leaves (data not shown); however, distinct differences were found in the morphology and dry weight of roots (Figure 1). When the aboveground plant weight (stems and leaves) and underground plant weight (roots) were compared, the ratio of the stem and leaf: root was 2:1 under ASL irradiation, while the ratio under LED irradiation condition was 4:1, representing a significant decrease in root growth (Table 1). Thus, this shows that LED controlled root growth. 


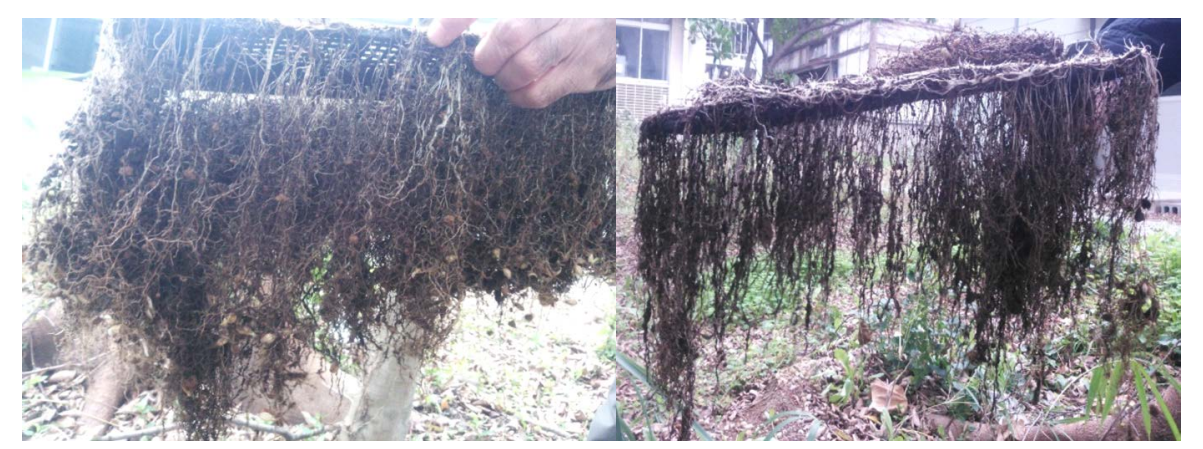

(a)

(b)

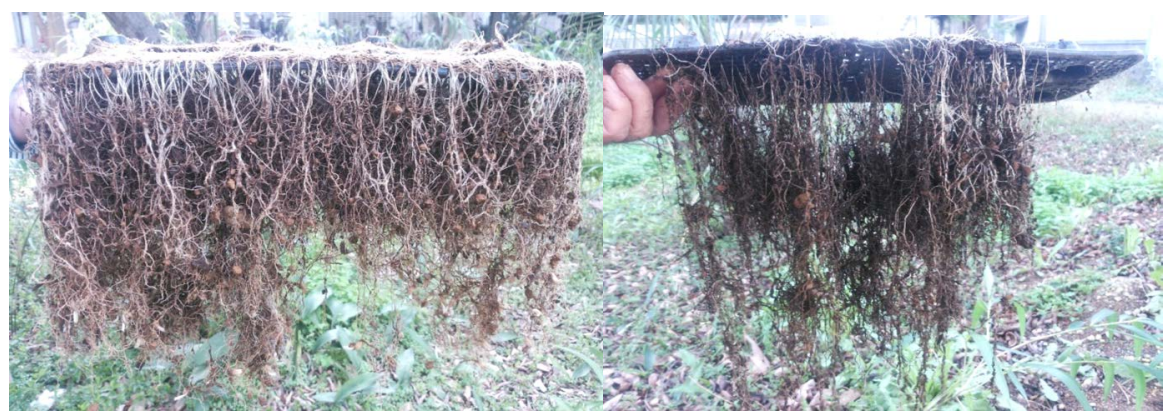

(c)

(d)

Figure 1. Effect of four light sources on the morphology of roots in young green barley. (a) ASL 200; (b) ASL 300; (c) R4:G1:B1 200; (d) R9:B1 $200\left(\mu \mathrm{mol} \mathrm{mL}^{-2} \cdot \mathrm{s}^{-1}\right)$.

Table 1. Dry weight of young green barley grown under four light sources.

\begin{tabular}{ccccc} 
& \multicolumn{4}{c}{ Dry weight $(\mathrm{g})$} \\
\cline { 2 - 5 } & RB-LEDs $\left(200^{\mathrm{a}}\right)$ & RGB-LEDs $\left(200^{\mathrm{a}}\right)$ & ASL $\left(200^{\mathrm{a}}\right)$ & ASL $\left(300^{\mathrm{a}}\right)$ \\
\hline Leaves & 21.66 & 24.42 & 25.74 & 33.37 \\
Roots & 6.71 & 6.51 & 13.02 & 12.26 \\
\hline
\end{tabular}

a. The photon density of unit was $\mu \mathrm{mol} \mathrm{mL}^{-2} \cdot \mathrm{s}^{-1}$.

\subsection{Effect of Irradiation Using Three Sources of Light of Fixed Photon Density on the Amino Acid Content in Young Green Barley}

The amino acid content in barley grown under LED-RB irradiation was twice the amount of that in plants grown under ASL irradiation, and those grown under RGB irradiation had 1.5-fold higher amino acid content than that in the ASL-irradiated plants. A significant increase in amino acid content was found in plants grown under both LEDs compared with the plant grown under ASL irradiation (Table 2).

\subsection{Effect of Irradiation with Three Sources of Light with Fixed Photon Density on the CG Content of Young Green Barley}

Some studies conducted on corn plants have reported that CGs are involved in cell defense and can counter light stress [12]. Three sources of light with fixed photon densities were used, and differences in the CG content in plants were measured. Four kinds of CGs, southerlandin (1), osmaronin (2), epidermin (3), and epiheterodendrin (4) were isolated from young green barley grown under the three different sources of light. These CGs were identified and their levels were measured (Table 3). The total CG content in plants grown under the ASL and LED-RB conditions was $84.1 \mathrm{mg}$ and $80.4 \mathrm{mg}$, respectively. Meanwhile, $100.4 \mathrm{mg}$ of total CGs was measured in the plant grown under LED-RGB irradiation, indicating an approximate $20 \%$ increase compared with those grown under the other two light sources. Under ASL irradiation, the epidermin content was particularly low, and under LED-RB irradiation, the osmaronin content was as low as $10.7 \%$. 
Table 2. The amino acid composition of young green barley grown under different culture conditions.

\begin{tabular}{|c|c|c|c|c|c|c|}
\hline & \multicolumn{6}{|c|}{ Amino acid contents (g/100g dry weight) } \\
\hline & \multirow{2}{*}{ ASL } & \multirow{2}{*}{ RB-LEDs } & \multirow{2}{*}{ RGB-LEDs } & RB-LEDs & RGB-LEDs & RB-LEDs \\
\hline & & & & ASL & ASL & RGB-LEDs \\
\hline Arginine & 0.59 & 1.20 & 0.86 & 2.0 & 1.5 & 1.4 \\
\hline Lysine & 0.75 & 1.46 & 1.06 & 1.9 & 1.4 & 1.4 \\
\hline Histidine & 0.27 & 0.59 & 0.40 & 2.2 & 1.5 & 1.5 \\
\hline Phenylalanine & 0.59 & 1.09 & 0.87 & 1.8 & 1.5 & 1.3 \\
\hline Tyrosine & 0.40 & 0.77 & 0.59 & 1.9 & 1.5 & 1.3 \\
\hline Leucine & 0.93 & 1.74 & 1.33 & 1.9 & 1.4 & 1.3 \\
\hline Isoleucine & 0.47 & 0.91 & 0.67 & 1.9 & 1.4 & 1.4 \\
\hline Methionine & 0.23 & 0.41 & 0.31 & 1.8 & 1.3 & 1.3 \\
\hline Valine & 0.65 & 1.20 & 0.94 & 1.8 & 1.4 & 1.3 \\
\hline Alanine & 0.76 & 1.37 & 1.09 & 1.8 & 1.4 & 1.3 \\
\hline Glycine & 0.64 & 1.13 & 0.90 & 1.8 & 1.4 & 1.3 \\
\hline Proline & 0.55 & 1.01 & 0.79 & 1.8 & 1.4 & 1.3 \\
\hline Glutamic acid & 1.08 & 2.26 & 1.59 & 2.1 & 1.5 & 1.4 \\
\hline Serine & 0.54 & 0.97 & 0.76 & 1.8 & 1.4 & 1.3 \\
\hline Threonine & 0.54 & 1.04 & 0.80 & 1.9 & 1.5 & 1.3 \\
\hline Aspartic acid & 1.07 & 2.24 & 1.71 & 2.1 & 1.6 & 1.3 \\
\hline Tryptophan & 0.23 & 0.41 & 0.36 & 1.8 & 1.6 & 1.1 \\
\hline Cystine & 0.16 & 0.26 & 0.23 & 1.6 & 1.4 & 1.1 \\
\hline Moisture content (\%) & 91.7 & 93.0 & 93.0 & & & \\
\hline
\end{tabular}

Table 3. Contents of cyanogenic glucoside (CGs) of young green barley grown under three light sources.

\begin{tabular}{cccc}
\hline \multirow{2}{*}{ CGs } & \multicolumn{3}{c}{ CGs contents (mg/100g fresh weight) } \\
\cline { 2 - 4 } & ASL & RB-LEDs & RGB-LEDs \\
\hline Epiheterodendrin (1) & 12.3 & 14.5 & 19.4 \\
Osmaronin (2) & 30.1 & 10.7 & 27.9 \\
Sutherlandin (3) & 38.7 & 38.4 & 36.9 \\
Epidermin (4) & 3.1 & 16.9 & 16.2 \\
Total CGs (mg/100g) & 84.1 & 80.4 & 100.4 \\
\hline
\end{tabular}

\subsection{Effect of Irradiation with Three Sources of Light with Fixed Photon Density on N Content in the Stem, Leaf, and Roots of Young Green Barley}

The percentage of total $\mathrm{N}$ content in young green barley was almost the same in plants grown under LED-RB and LED-RGB irradiation, while that in plants grown under ASL was approximately $70 \%$ of that in the LED condition (Table 4). The percentage of total $\mathrm{N}$ in the root was the following order: LED-RB $>$ LED-RGB = ASL, which shows the difference in the percentage of total $\mathrm{N}$ in the stem and leaf, and in the root. In addition, the ratio of the $\mathrm{N}$ content in root to that in the stem and leaf was 36.3\% for the plant grown under the LED-RBG irradiation, and that was the lowest value among the plants grown under the three different sources of light (Table 5).

\subsection{Effect of Different Photon Densities under ASL Irradiation on the Growth and Amino Acid Content of Young Green Barley}

Under ASL irradiation, differences in the growth of barley plants were compared when the photon density received at the tip of the longest leaf was controlled as $200 \mu \mathrm{mol} \mathrm{mL} \mathrm{mL}^{-2} \cdot \mathrm{s}^{-1}$ and $300 \mu \mathrm{mol} \mathrm{mL}{ }^{-2} \cdot \mathrm{s}^{-1}$. By increasing the photon density as $200 \mu \mathrm{mol} \mathrm{mL} \mathrm{m}^{-2} \cdot \mathrm{s}^{-1}$ to $300 \mu \mathrm{mol} \mathrm{mL} \mathrm{m}^{-2} \cdot \mathrm{s}^{-1}$, the plant growth rate increased by $4.2 \%$ and the weight increased by $15.8 \%$ on the day 10 (data not shown), and the amino acid content increased by $10 \%$ at a higher photon density level (Table 6). 
Table 4. Nitrogen contents (g/100 g dry weight) of young green barley grown under three light sources.

\begin{tabular}{cccc}
\hline & \multicolumn{3}{c}{ Nitrogen contents (g/100g dry weight) } \\
\cline { 2 - 4 } & ASL & RB-LEDs & RGB-LEDs \\
\hline Total nitrogen & 1.9 & 2.8 & 2.6 \\
\hline
\end{tabular}

Table 5. Nitrogen contents (mg/1g dry weight) of young green barley grown under three light sources.

\begin{tabular}{cccc}
\hline & & Nitrogen contents (mg/1g dry weight) & \\
\cline { 2 - 4 } & ASL & RB-LEDs & RGB-LEDs \\
\hline Leaves & 20.6 & 30.3 & 26.2 \\
Roots & 9.2 & 12.9 & 9.5 \\
Roots/leaves (\%) & 44.7 & 42.6 & 36.3 \\
\hline
\end{tabular}

Table 6. Amino acid compositions of young green barley leaves grown under different photon density conditions of ASL.

\begin{tabular}{cccc}
\hline & & Amino acid contents $(\mathrm{g} / 100 \mathrm{~g}$ dry weight $)$ & ASL 300 \\
& ASL & ASL & ASL 200 \\
Arginine & 0.59 & $300 \mathrm{mLl} \mathrm{m}^{-2} \cdot \mathrm{s}^{-1}$ & 1.1 \\
Lysine & 0.75 & 0.67 & 1.0 \\
Histidine & 0.27 & 0.77 & 1.1 \\
Phenylalanine & 0.59 & 0.29 & 1.1 \\
Tyrosine & 0.40 & 0.66 & 1.1 \\
Leucine & 0.93 & 0.45 & 1.1 \\
Isoleucine & 0.47 & 1.03 & 1.1 \\
Methionine & 0.23 & 0.51 & 1.0 \\
Valine & 0.65 & 0.23 & 1.1 \\
Alanine & 0.76 & 0.72 & 1.1 \\
Glycine & 0.64 & 0.82 & 1.1 \\
Proline & 0.55 & 0.70 & 1.1 \\
Glutamic acid & 1.08 & 0.60 & 1.2 \\
Serine & 0.54 & 1.26 & 1.1 \\
Threonine & 0.54 & 0.58 & 1.1 \\
Aspartic acid & 1.07 & 0.60 & 1.1 \\
Tryptophan & 0.23 & 1.16 & 1.2 \\
Cystine & 0.16 & 0.28 & 1.1 \\
Moisture content (\%) & 91.7 & 0.18 & \\
\hline
\end{tabular}

\section{Discussion}

A significant morphological difference was observed in the underground part (root) of barley grown under ASL and LED irradiation, both of which had the same photon density. The amount of root growth under ASL irradiation was twice the amount of that under LED irradiation (Figure 1). Meanwhile, there was no significant difference found for the aboveground part of plants, as there was only a $20 \%$ decrease in stem and leaf growth in the plant under LED-RB compared with that in the plant under ASL irradiation. In barley cultivation, LED irradiation inhibited root growth, which accounted for the underground part of the plant. This may be due to the difference in nutrient requirement. In order for plant to synthesize chlorophyll, red (R: $450 \mathrm{~nm})$ and blue (B: $660 \mathrm{~nm})$ wavelengths of light are required; whereas for plant morphosis, blue (B: $660 \mathrm{~nm})$ light is required. In other words, as LED irradiation provides a wavelength mainly composed of red and blue light, the metabolism necessary for growth of the aboveground part of the plant dominates, and the metabolism required for the growth of the underground part (root) is limited. Metabolism in the above-ground part of the plants (stem and leaf) under ASL irradiation, which covers a wide range of wavelengths, was more active than that in plants under LED irradiation. 
Therefore, it is hypothesized that the demand for various nutrients in the aboveground part of plants is increased under ASL irradiation, and roots under ASL irradiation grew almost twice as much as those under LED irradiation. This is because plants need to obtain more nutrients from the soil under this condition. The difference in metabolism in the aboveground part of the plant was expected, because the dry weight of the aboveground part (stems and leaves) of the plant grown under RGB-LED, which has a similar wavelength to ASL, was similar to that of the plant grown under ASL.

Amino acid content in young green barley grown under LED-RB irradiation was twice that of the plant grown under ASL irradiation, and 1.4 times more than that under LED-RGB irradiation, in which both the ASL and LED-RB irradiation had the same photon density at $200 \mu \mathrm{mol} \mathrm{mL}{ }^{-2} \cdot \mathrm{s}^{-1}$. Our previous report [14] also showed that LED-R9:B1 was superior to other sources of light for amino acid synthesis. There was increased amino acids synthesis in young green barley produced under LED irradiation than in the plant grown under ASL irradiation. As LED-RB emits a wavelength indispensable for photosynthesis (chlorophyll synthesis) and morphosis, a large concentration of amino acids is required for the synthesis of cytoplasm to form cells of young green barley during the growing period. Because of this, it is thought that cultivation under LED-RB irradiation can induce a significant increase in amino acid content.

It was revealed that cultivation under LED irradiation caused an increase in the amount of amino acid content; however, some studies using corn plants have showed that cultivation under a limited range of wavelengths is stressful for the plant [13]. In the present study, the CG content was measured in young green barley that was grown under three sources of light. Four kinds of CGs were isolated and identified, however, dihydroosmaronin, which was identified by Poumohseni et al., was not isolated in this study [18]. The amount of total CG can be shown as follows; LED-RGB > ASL > LED-RB, and the epidermin content in the plant under ASL irradiation was as low as $3.7 \%$. It is supposed that this low amount of epidermin was caused by the introduction of hydroxyl group to 3-methylbutyronitrile, and the subsequent synthesis of epidermin, both of which were proposed by Nielsen et al. as the biosynthetic processes of barley CGs [9], which were restrained under ASL irradiation. Comparing the CG content in plants grown under different light sources, the CG content under LED-RB irradiation was approximately 20\% less than that under LED-RGB irradiation, and approximately 4\% less than that under ASL irradiation. This implies that LED-RB irradiation is a source of stress to young green barley. The accumulation of CGs increases under dark conditions in corn plant, while the level of CGs decreases under strong light [13]. This is because plants cope with light stress by breaking down CGs, and their subsequent use as "scavengers" in the breakdown of CG to amide and sugar, in order to remove active oxygen [12]. In barley plants, LED-RB irradiation, which has a limited range of wavelengths, induces light stress in plants; it is thought that the CG content in stems and leaves is decreased because plants can protect themselves from light damage by breaking down the accumulated CGs and having them work as scavengers. This is a consistent with the hypothesis put forward by Moller et al. [12].

Meanwhile, Selmar et al. suggested that CGs may play an important role in primary metabolism as an $\mathrm{N}$ and glucose transporter [19]. Based on the presumption made by Forslund and Jonsson [8] that barley CGs may contribute to the accumulation of $\mathrm{N}$, the $\mathrm{N}$ content of samples grown under the three sources of light irradiation were compared (Table 4). It is supposed that the $\mathrm{N}$ content increased as plants degraded CGs to counter the light stress induced under LED-RB light, and that $\mathrm{N}$ accumulated in the stems and leaves through this process (Table 5).

It became clear that LED-RB was more effective at increasing amino acid synthesis in barley cultivation, compared with ASL, which imitates natural sun light, and LED-RBG whose wavelength is similar to that of sun light. The reason why the CG content was lowest in the plant grown under the LED-RB irradiation, was probably because the limited range of the LED-RB wavelength was stressful to barley plant, and as a result, amino acid content increased.

To clarify the effect of photon density on the growth of young green barley, a growth test was conducted under different photon densities, which were set as 200 and $300 \mu \mathrm{mol} \mathrm{mL}{ }^{-2} \cdot \mathrm{s}^{-1}$. The increases in the growth (4.2\%) and the weight (15.8\%) were found under irradiation where the photon density was increased by $100 \mu \mathrm{mol} \mathrm{mL}^{-2} \cdot \mathrm{s}^{-1}$. Furthermore, the amino acid content increased by 10\%. This result is consistent with that observed in rice plants, in which an increase in photon density brought about an increase in N content in rice leaf under LED-R9: B1 irradiation [20].

\section{Conclusion}

In barley cultivation, LED irradiation inhibited root growth, which accounted for the underground part of the plant. 
A significant increase in amino acid content was found in plants grown under both LEDs compared with the plant grown under ASL irradiation. And comparing the CG content in plants grown under different light sources, the CG content under LED-RB irradiation was approximately $20 \%$ less than that under LED-RGB irradiation, and approximately $4 \%$ less than that under ASL irradiation. The $\mathrm{N}$ contents of young green barley grown under the three sources of light irradiation were compared. It was supposed that the $\mathrm{N}$ content increased as plants degraded CGs to counter the light stress induced under LED-RB light, and that $\mathrm{N}$ accumulated in the stems and leaves through this process.

\section{References}

[1] Bendet, J.A., Umeda, H. and Shibamoto, T. (2007) Antioxidant Activity of Flavonoids Isolated from Young Green Barley Leaves toward Biological Lipid Samples. Journal of Agriculture and Food Chemistry, 55, 5499-5504. http://dx.doi.org/10.1021/jf070543t

[2] Kamiyama, M. and Shibamoto, T. (2012) Flavonoids with Potent Antioxidant Activity Found in Young Green Barley Leaves. Journal of Agricultural and Food Chemistry, 60, 6260-6267. http://dx.doi.org/10.1021/jf301700j

[3] Okawa, M., Kinjo, J., Hasegawa, H., Ueyama, Nakamura, K., Ishikawa, R. et al. (1998) Three New Anti-Oxidative Saponarin Analoges from Young Green Barley Leaves. Chemical \& Pharmaceutical Bulletin, 46, 1887-1890. http://dx.doi.org/10.1248/cpb.46.1887

[4] Ueyama, H., Aotsuka, Y., Okawa, M., Ogura, Y., Ukeguchi, M., Hoashi, K. and Kinjo, J. (2011) Antioxidant Activities of Lutonarin Isolated from Young Barley Leaves. Nippon Shokuhin Kagaku Kogaku Kaishi, 58, 170-172. http://dx.doi.org/10.3136/nskkk.58.170

[5] Paulickova, I., Ehrenbergerova, J., Fiedlerova, V., Gabrovska, D., Havlova, P., Holasova, M. et al. (2006) Evaluation of Barley Grass as a Potential Source of Some Nutritional Substances. Czech Journal of Food Sciences, 25, 65-72.

[6] Lee, N.Y., Lee, M.J., Kim, Y.K., Park, H.K., Choi, J.S., Hyun, J.N. et al. (2010) Effect of Light Emitting Diode Radiation on Antioxidant Activity of Barley Leaf. Journal of Korean Society for Applied Biological Chemistry, 53, 685-690. http://dx.doi.org/10.3839/jksabc.2010.104

[7] Unbonavičiūtè, A., Samuolienė, G., Brazaitytè, A., Ruzgas, V., Šabajevienė, G., Šliogerytė, K. et al. (2009) The Effect of Light Quality on the Antioxidative Properties of Green Barley Leaves. Scientific Works of the Lithuanian Institute of Horticulture and Lithuanian University of Agriculture. Sodininkyste ir Darzininkyste, 28, 153-161.

[8] Forslund, K., and Jonsson, L. (1997) Cyanogenic Glycosides and Their Metabolic Enzymes in Barley, in Relation to Nitrogen Levels. Physiologia Plantarum, 101, 367-372. http://dx.doi.org/10.1111/j.1399-3054.1997.tb01010.x

[9] Nielsen, A.K., Olsen, E.C., Pontoppidan, K. and Møller, L.B. (2002) Leucine-Derived Cyano Glycosides in Barley. Plant Physiology, 129, 1066-1075. http://dx.doi.org/10.1104/pp.001263

[10] Koch, B.M., Sibbesen, O., Halkier, B.A., Svendsen, I. and Moller, B.L. (1995) The Primary Sequence of Cytochrome P450tyr, the Multifunctional N-Hydroxylase Catalyzing the Conversion of L-Tyrosine to p-Hydoxyphenylacetaldehyde Oxime in the Biosynthesis of the Cyanogenic Glucoside Dhurrin in Sorghum bicolor (L.) Moench. Archives of Biochemitry and Biophysics, 323, 177-186. http://dx.doi.org/10.1006/abbi.1995.0024

[11] Jones, P.R., Møller, B.L. and Høj, P.B. (1999) The UDP-Glucose: p-Hydroxymandelonitrile-O-Glucosyltransferase that Catalyzes the Last Step in Synthesis of the Cyanogenic Glucoside Dhurrin in Sorghum biolor. The Journal of Biological Chemistry, 274, 35483-35491. http://dx.doi.org/10.1074/jbc.274.50.35483

[12] Møller, B.L. (2010) Functional Diversifications of Cyanogenic Glucosides. Current Opinion in Plant Biology, 13, 337346. http://dx.doi.org/10.1016/j.pbi.2010.01.009

[13] Adewusi, S.R.A. (1990) Turnover of Dhurrin in Green Sorghum Seedlings. Plant Physiology, 94, 1219-1224. http://dx.doi.org/10.1104/pp.94.3.1219

[14] Koga, R., Meng, T., Nakamura, E., Miure, C., Irino, N., Devkota, H.P., et al. (2013) The Effect of Photo-Irradiation on the Growth and Ingredient Composition of Young Green Barley (Hordeum vulugare). Agricultural Sciences, 4, 185194. http://dx.doi.org/10.4236/as.2013.44027

[15] Hossen, M.Z. (2007) Light Emitting Diodes Increase Phenolics of Buckwheat (Fagopyrum esculentum) Sprouts. Journal of Plant Interactions, 2, 71-78. http://dx.doi.org/10.1080/17429140701288228

[16] Folta, K.M. and Maruhnich, S.A. (2007) Green Light: A Signal to Slow Down or Stop. Journal of Experimental Botany, 58, 3099-3111. http://dx.doi.org/10.1093/jxb/erm130

[17] Sun, J., Nishio, J.N. and Vogelmann, T.C. (1998) Green Light Drives $\mathrm{CO}_{2}$ Fixation Deep within Leaves. Plant and Cell Physiology, 39, 1020-1026. http://dx.doi.org/10.1093/oxfordjournals.pcp.a029298

[18] Poumohseni, H., Ibenthal, W.D., Machinek, R., Remberg, G. and Wray, V. (1993) Cyanoglucosides in the Epidermis 
of Hordeum vulgare. Phytochemistry, 33, 295-297. http://dx.doi.org/10.1016/0031-9422(93)85506-M

[19] Selmar, D., Lieberei, R. and Biehl, B. (1988) Mobilization and Utilization of Cyanogenic Glycosides: The Linustatin Pathway. Plant Physiology, 86, 711-716. http://dx.doi.org/10.1104/pp.86.3.711

[20] Matsuda, R., Ohashi-Kaneko, K., Fujiwara, K., Goto, E. and Kurata, K. (2004) Photosynthetic Characteristics of Rice Leaves Grown under Red Light with or without Supplemental Blue Light. Plant and Cell Physiology, 45, 1870-1874. http://dx.doi.org/10.1093/pcp/pch203 
Scientific Research Publishing (SCIRP) is one of the largest Open Access journal publishers. It is currently publishing more than 200 open access, online, peer-reviewed journals covering a wide range of academic disciplines. SCIRP serves the worldwide academic communities and contributes to the progress and application of science with its publication.

Other selected journals from SCIRP are listed as below. Submit your manuscript to us via either submit@scirp.org or Online Submission Portal.
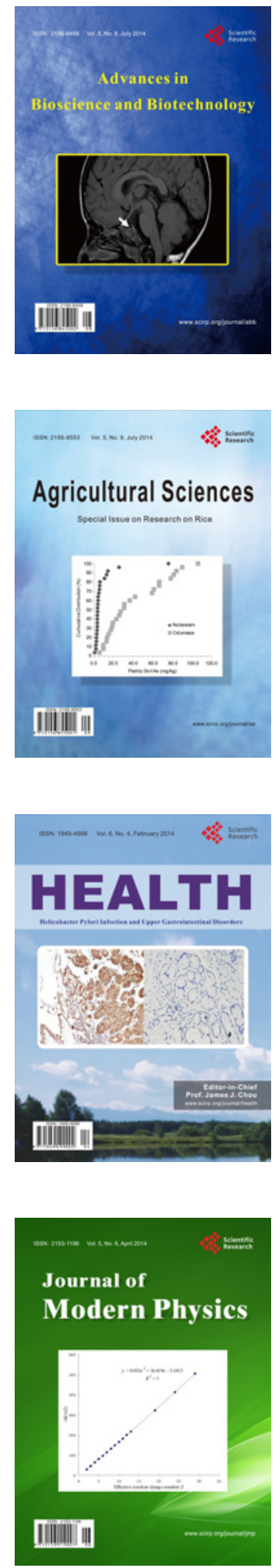
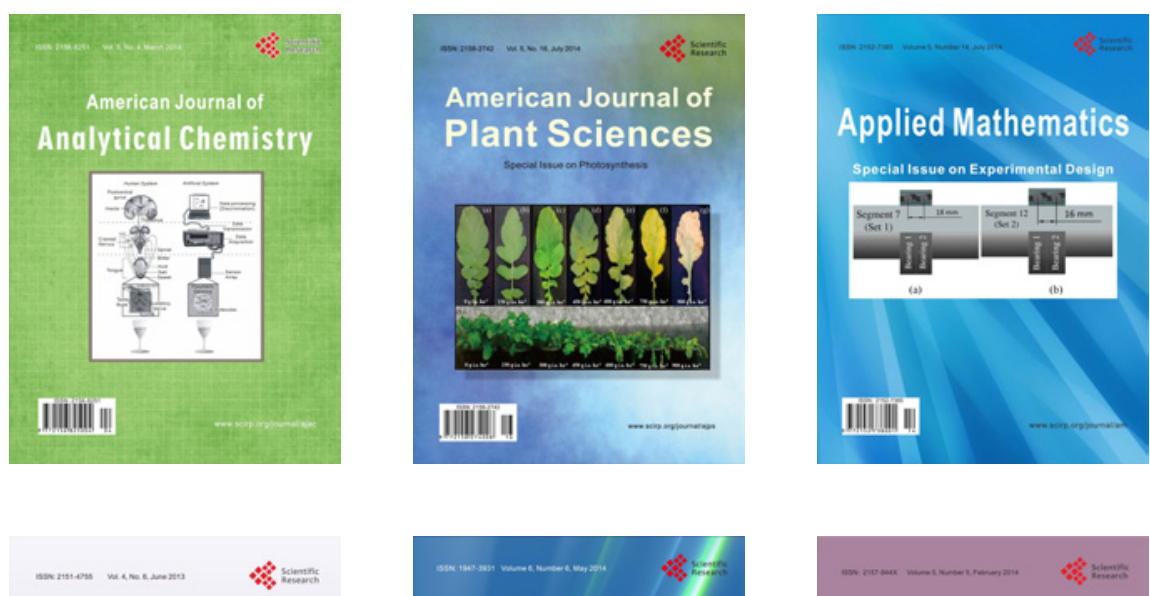

Creative Education
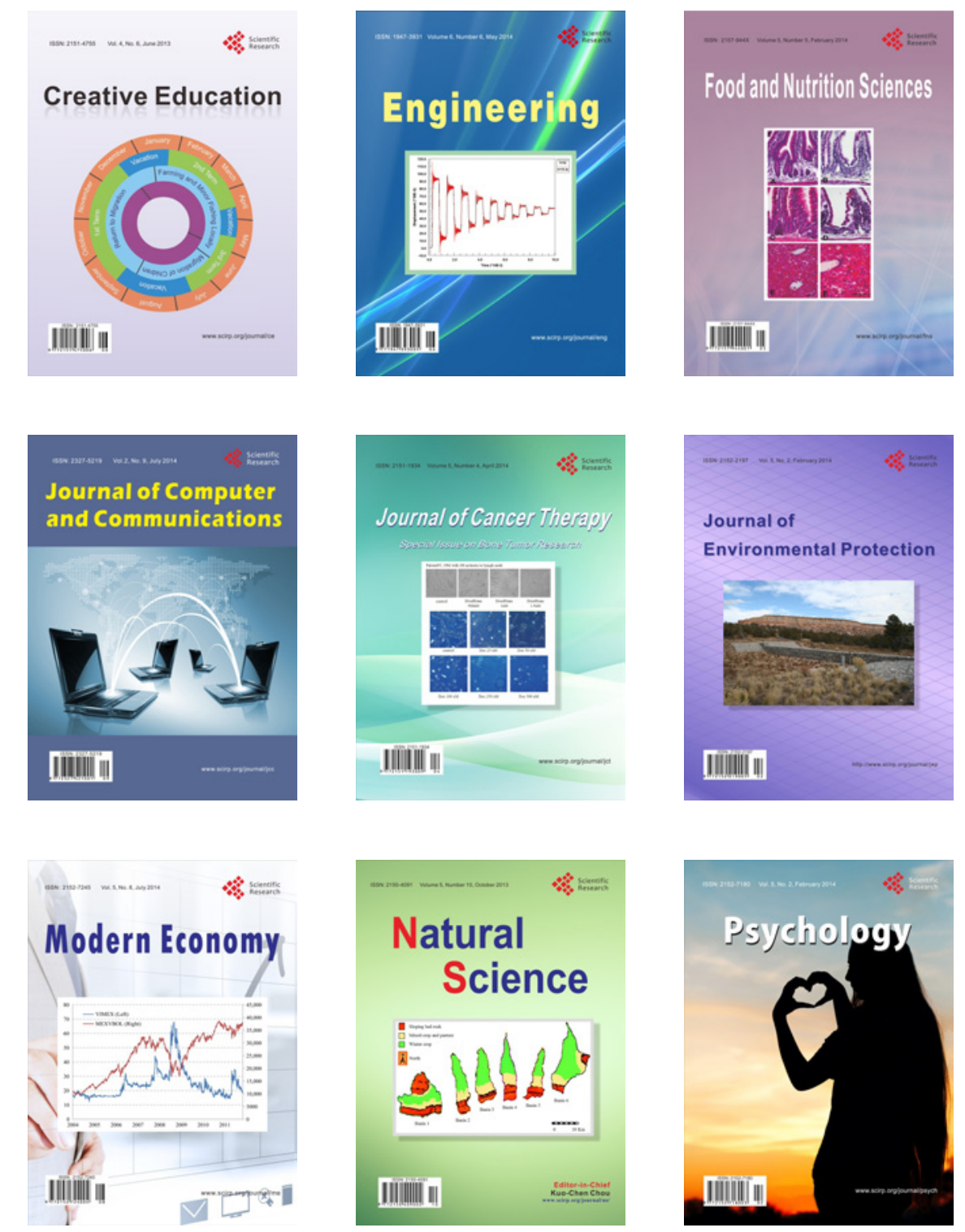